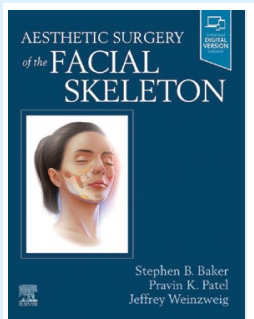

\section{AESTHETIC SURGERY OF THE FACIAL SKELETON}

Stephen B. Baker, Pravin K. Patel, Jeffrey Weinzweig; 2021; Elsevier; $£ 203.99 ;$ pp. xiv+512.

ISBN 978-0-323-48410-7; E-book: ISBN 978-0-32368052-3; Inkling ISBN 978-0-323-68051-6

The editorial triumvirate has assembled a diverse coterie of authorities from different disciplines focused on the human face. With a list of no fewer than 71 contributors, this multi-authored text delves into a multiplicity of perspectives on facial skeletal reconstructions.

The book is divided into four sections dealing with, respectively: the principles of facial surgery; details of the underlying skeletal framework; the overlying soft tissues and cutaneous coverings; and finally special case considerations. Each chapter is prefaced by 'Key points', a summary and references.

The heavily illustrated multi-coloured text is superbly backed up with extensive references ranging from 1893 to the most recent. The multi-dimensional approach to each surgical challenge enlarges the scope of possible treatment modalities of specific conditions.

The various authors' contributions are subjected to terminal editorial commentaries in each chapter, making for thoughtful, detailed reconsiderations of the recommended surgical procedures. Most notable is the chapter on 'Face transplantation' pioneering advanced techniques in facial reconstruction.

The surgical components of facial reconstruction are predicated upon a full understanding of the fundamental embryonic developmental constituents of the facial skeleton, to which a chapter is devoted.

Reading and absorbing the full contents of this tome would be equivalent to attending a detailed postgraduate seminar requiring determined dedication.

A feature to activate the eBook version, providing the power to browse and search specific content, to view enhanced images and to take notes is provided by a hidden code on the inner cover, revealed by scratching off a surface overlay. In doing so, the first individual redeeming the PIN precludes the transfer of the eBook to another party. This identity feature ensures the eBook's content is confined to the initial purchaser or reader.

In summary, this book is a compendium of diverse disciplines devoted to the surgical restoration of the most distinctive components of the human countenance. This tome will contribute to further advances in the complex field of facial surgical innovations and is highly recommended.

Geoffrey H. Sperber

\title{
BDA back CQC moves on remote orthodontics
}

The British Dental Association (BDA) has applauded moves by the Care Quality Commission (CQC) requiring remote orthodontic providers to be registered with them in order to practise lawfully.

The CQC has stated that remote orthodontics comes under the regulated activities of 'Treatment of disease, disorder or injury' and 'Diagnostic and screening procedures', and as such requires registration and by extension inspection.

The CQC also noted that 'to register with us, providers must assure us that they are able to provide safe and effective care in line with relevant legislation and guidance' and has indicated its willingness to prosecute providers who fail to register.

Remote provision is growing in popularity, but can lead to irreversible damage to a patient's mouth.

BDA Chair Eddie Crouch said: 'With remote orthodontics we need real regulation, not just empty warnings to properly protect patients. Mandatory CQC registration and inspection is a much-needed first step. A health watchdog needs teeth, and a willingness to prosecute those who fail to register is sending the right signal to unscrupulous operators.'

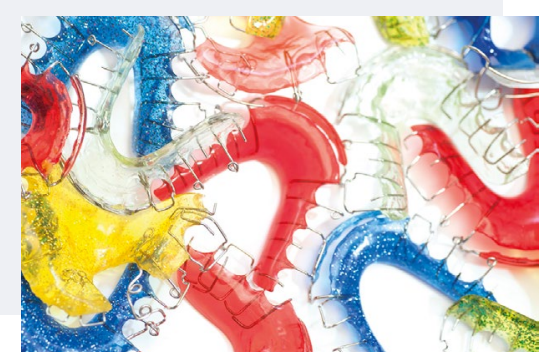

